\title{
Validity and reliability of faecal antigen test in identifying $h$. Pylori infection in adults with dyspepsia
}

\author{
Senthil Kumar $K^{1}$, Dinesh Kumar $\mathbf{T}^{2}$, Balamuralee $\mathbf{R}^{3}$, Anantharamakrishnan $\mathbf{R}^{4}$ \\ ${ }^{1}$ Dr. K. Senthil Kumar, Associate Professor, ${ }^{2}$ Dr. T. Dinesh Kumar, Assistant Professor, ${ }^{3}$ Dr. Balamuralee R, Postgraduate, \\ ${ }^{4}$ Dr. R. Anantharamakrishnan, Professor, all authors are affiliated with Department of General Surgery, Chettinad Hospital \& \\ Research Institute, I.T. Highway, Kelambakkam, Kanchipuram District, Tamil Nadu 603 103, India.
}

Address for Correspondence: Dr. K. Senthil Kumar, Associate Professor, Department of General Surgery, Chettinad Hospital \& Research Institute, I.T. Highway, Kelambakkam, Kanchipuram District. Email: rbmleergs@gmail.com

\begin{abstract}
Background: H. Pylori is one of underdiagnosed and undertreated in many developing countries, including in India. Faecal antigen test, which is a noninvasive, simple to conduct screening test is reported to be ideal for resource limited settings like India. But the reported validity and reliability of the test is quite variable and studies on the subject in Indian population are scarce. Objectives: To assess the validity and reliability of faecal antigen test in diagnosis of H. Pylori in adult with dyspepsia. Materials and methods: The current study is a prospective observational study conducted in a single tertiary care teaching hospital located in south India. Adults between 20 to 49 years, with symptoms of dyspepsia were included. Giemsa staining of Antral mucosal biopsy specimen was considered as gold standard. Faecal antigen test was conducted by ELISA. Sensitivity, specificity, predictive values and reliability (kappa statistic) were assessed. Results: Faecal antigen positivity was seen in $57(71.25 \%)$ subjects, The Antral mucosal biopsy has given 59 (73.8\%) positive results, The sensitivity, Specificity of the faecal antigen test were $94.92 \%$ (95\% CI 89.30 to $100.5 \%), 95.24 \%$ (86.12\% to $104.3 \%)$ respectively. The positive and negative predictive values were $98.25 \%(94.83 \%$ to $101.6 \%)$ and $86.96 \%(73.19 \%$ to $100.7 \%)$ respectively. The overall diagnostic accuracy was $95 \%(90.22 \%$ to $99.77 \%)$. Reliability as measured by kappa statistic was 0.875 ( $\mathrm{P}$ value $<0.001)$. Conclusions: Faecal antigen test has shown good validity and reliability in diagnosis of H. pylori infection.
\end{abstract}

Keywords: Faecal antigen test, h. Pylori infection, validity and reliability

\section{Introduction}

Helicobacter. Pylori is implicated in wide range of gastro intestinal diseases, in all age groups [1]. These diseases range from benign condition like gastritis and peptic ulcer disease to malignant conditions like mucosa-associated lymphoid tissue (MALT) lymphoma and gastric cancer [2-5]. The reported burden of $H$. pylori infection across the globe is quite variable in different population groups. The socio demographic conditions, eating habits etc are reported to contribute to this variability $[6,7]$. But in majority of the developing countries, H.Pylori infection is considered as one of the most underdiagnosed and hence under treated conditions. In adequate resources and poor availability of the diagnostic tests is an important reason for this $[8,9]$. Various noninvasive, simple to perform and economical screening test have been evaluated for their utility in diagnosis of $\mathrm{H}$. Pylori infection in these resource limited settings [10-12]. Out of this faecal antigen testing

Manuscript Received: $5^{\text {th }}$ December 2016

Reviewed: $15^{\text {th }}$ December 2016

Author Corrected: $24^{\text {th }}$ December 2016

Accepted for Publication: $31^{\text {st }}$ December 2016 by various methods has been specially touted as high utility screening test in large population groups and children $[13,14]$. But the reported sensitivity, specificity of this screening method are quite varied across the studies [13-25]. Hence documenting the validity of this screening tool in a particular population group is essential to make appropriate recommendations for its routine use.

Objectives: 1) To assess the validity of faecal antigen test (by ELISA) in diagnosis of H.Pylori infection against antral mucosal biopsy. 2) To assess the reliability of the faecal antigen test in diagnosis of $\mathrm{H}$. Pylori infection as compared to antral mucosal biopsy

\section{Materials and Methods}

Study Setting: The study was conducted in the department of General Surgery Chettinad Hospital and Research Institute, which is a tertiary care teaching hospital. 
Study design: The study was a prospective observational study.

Study population: The study subjects were patients with symptoms of gastritis and dyspepsia seeking treatment from general surgery outpatient department in the study setting.

Study duration: The data collection for the study was conducted between June 2014 to June 2016

\section{Inclusion criteria:}

1) All patients with gastritis and dyspeptic symptoms

2) Age group 15 - 50 years

3) Both genders

Exclusion criteria: Patients who are contraindicated for Upper Gastro Intestinal endoscopy.

Sampling method: All the eligible subjects who were willing to participate in the study were sequentially recruited in to the study by convenient sampling, till the required sample size is reached.

Study procedure: All the patients presenting to the OPD with symptoms of dyspepsia, satisfying inclusion and exclusion criteria were included in the study. After

\section{Original Research Article}

thorough clinical history and physical examination, Upper gastro intestinal endoscopy and biopsy was taken from each participant. The specimen was stained with Giemsa staining and assessed for presence of H. Pylori. Stool sample was collected from each participant and was tested for Faecal H. Pylori Antigen by Enzyme linked Immunosorbent Assay (ELISA)

Ethical considerations: The study was approved by institutional human ethics committee. Informed written consent was obtained from all the study participants, after explaining the purpose of the study, the risk and benefits involved and voluntary nature of their participation. (Annexure II) Confidentiality of the study participants was maintained throughout the study period.

Statistical methods: The diagnosis of Pylori by the Giemsa staining was considered as the gold standard in the study. The diagnosis by faecal antigen testing was considered as the explanatory variable. The validity (sensitivity \& Specificity) and predictive values of faecal antigen test in diagnosing $\mathrm{H}$. Pylori were calculated along with their $95 \%$ CI. The reliability of Serum markers and urea breath test in diagnosing Pylori were assessed by calculating kappa statistic and it's p value. IBM SPSS statistical software version 21 was used for statistical analysis.

\section{Observations \& Results}

A total of 80 participants were included in the final analysis.

Table1: Descriptive analysis of socio demographic variables in study group $(\mathrm{N}=80)$.

\begin{tabular}{|c|c|c|c|}
\hline \multirow{2}{*}{ Age Groups } & Male & Female & \multirow{2}{*}{ Total } \\
\cline { 2 - 4 } & $19(39.6 \%)$ & $6(18.8 \%)$ & $25(31.3 \%)$ \\
\hline $20-29$ & $9(18.8 \%)$ & $10(31.3 \%)$ & $19(23.8 \%)$ \\
\hline $30-39$ & $20(41.7 \%)$ & $16(50.0 \%)$ & $36(45.0 \%)$ \\
\hline $40-49$ & $\mathbf{4 8}$ & $\mathbf{3 2}$ & $\mathbf{8 0}$ \\
\hline Total & &
\end{tabular}

Majority $(60 \%)$ of the participants were males and females constituted about $40 \%$ of the study subjects. Both among males and females, subjects between 40 to 49 years constituted highest proportion $(41.7 \%$ and $50 \%$ respectively). Among males $39.6 \%$ of the participants were between 20 to 29 years, whereas this proportion was only $18.8 \%$ in females. 30 to 39 year age group people constituted $18.8 \%$ of males and $31.3 \%$ of females. (Table1).

Table-2: Descriptive analysis of clinical variables in study group $(\mathrm{N}=\mathbf{8 0})$

\begin{tabular}{|c|c|c|}
\hline Parameter & Frequency & Percent \\
\hline I. Faecal Antigen & 57 & $71.25 \%$ \\
\hline Positive & 23 & $28.75 \%$ \\
\hline Negative & 59 & $73.75 \%$ \\
\hline II. Antral Mucosal Biopsy & 21 & $26.25 \%$ \\
\hline Positive & & \\
\hline Negative &
\end{tabular}


Faecal antigen positivity was seen in 57 (71.25\%) subjects, and the remaining $23(28.75 \%)$ were reported negative. The Antral mucosal biopsy has given 59 (73.8\%) positive results, with remaining $21(26.3 \%)$ participants reported negative by Antral mucosal biopsy (Table 2).

Table-3: Association of clinical variables with Antral Mucosal Biopsy (N=80).

\begin{tabular}{|c|c|c|c|c|}
\hline \multirow{2}{*}{ Faecal Antigen } & \multicolumn{2}{|c|}{ Antral Mucosal Biopsy } & \multirow{2}{*}{ Chi-Square Value } & \multirow{2}{*}{$P$ value } \\
\hline & Positive & Negative & & \\
\hline \multirow{2}{*}{ Positive } & 56 & 1 & \multirow{4}{*}{61.450} & \multirow{4}{*}{$<0.001$} \\
\hline & $98.25 \%$ & $1.75 \%$ & & \\
\hline \multirow{2}{*}{ Negative } & 3 & 20 & & \\
\hline & $13.04 \%$ & $86.96 \%$ & & \\
\hline
\end{tabular}

There was strong positive association between the Faecal antigen and Antral mucosal biopsy in study population, which was statistically significant $(\mathrm{P}$ value $<0.01$ ). There was strong positive association between the serum IgG and Antral mucosal biopsy in study population, which was statistically significant (P value $<0.01$ ) (Table 3).

Table-4: Validity and predictive values of FAECAL ANTIGEN test in study population (N=80)

\begin{tabular}{|c|c|c|c|}
\hline \multirow{2}{*}{ Parameter } & \multirow{2}{*}{ Value } & \multicolumn{2}{|c|}{ 95\% CI } \\
\cline { 3 - 4 } & & Lower & Upper \\
\hline Sensitivity & $94.92 \%$ & $89.30 \%$ & $100.5 \%$ \\
\hline Specificity & $95.24 \%$ & $86.12 \%$ & $104.3 \%$ \\
\hline False positive rate & $4.76 \%$ & $-4.34 \%$ & $13.87 \%$ \\
\hline False negative rate & $5.08 \%$ & $-0.52 \%$ & $10.69 \%$ \\
\hline Positive predictive value & $98.25 \%$ & $94.83 \%$ & $101.6 \%$ \\
\hline Negative predictive value & $86.96 \%$ & $73.19 \%$ & $100.7 \%$ \\
\hline Diagnostic accuracy & $95 \%$ & $90.22 \%$ & $99.77 \%$ \\
\hline
\end{tabular}

Faecal antigen had $94.92 \%$ sensitivity (95\% CI 89.30 to $100.5 \%), 95.24 \%$ specificity $(86.12 \%$ to $104.3 \%)$ in study population. The positive predictive value was $98.25 \%$ (94.83\% to $101.6 \%)$ and the negative predictive value was $86.96 \%$ (73.19\% to $100.7 \%)$ in study population. The overall diagnostic accuracy was $95 \%(90.22 \%$ to $99.77 \%)$ in study population (Table 4).

Table-5: Reliability of Faecal antigen test in diagnosing Pylori infection

\begin{tabular}{|c|c|c|c|}
\hline Measure of Agreement & Value & Std. Error $^{\mathbf{a}}$ & P value $^{<0.001}$ \\
\hline Kappa & .875 & .061 & $<0.000$ \\
\hline
\end{tabular}

The kappa statistic, which indicates the measurement of agreement between the two modalities (Faecal antigen and antral mucosal biopsy) was 0.875 , which indicated high degree of agreement. This was statistically significant $(\mathrm{P}$ value $<0.001)$

\section{Discussion}

The current study, which was conducted in a group of dyspeptic adults presenting to a tertiary care teaching hospital had included participants ranging from 20 to 49 years. Males in the age group of 40 to 49 years were predominant in the study. Faecal antigen positivity was seen in 57(71.25\%), whereas $59(73.8 \%$ ) ah shown positivity in Antral mucosal biopsy. There was strong positive association between the Faecal antigen and
Antral mucosal biopsy ( $\mathrm{P}$ value $<0.01)$. The results of both the tests indicate a high prevalence of $\mathrm{H}$. Pylori infection and corroborate with the reported incidence range by various previous studies $[1,6,26]$ The reported prevalence by various other Indian studies is quite varied $[4,27,28]$. In the current study, the sensitivity, Specificity of the Faecal antigen test were $94.92 \%$ (95\% CI 89.30 to $100.5 \%), 95.24 \%(86.12 \%$ to $104.3 \%)$ respectively. The 


\section{Original Research Article}

positive and negative predictive values were $98.25 \%$ (94.83\% to $101.6 \%)$ and $86.96 \%$ (73.19\% to $100.7 \%)$ respectively. The overall diagnostic accuracy was 95\% ( $90.22 \%$ to $99.77 \%)$. Reliability as measured by kappa statistic was 0.875 (P value $<0.001$ ). Study by Andrews J, who have compared validity of various stool antigen tests have documented sensitivity ranging from $56 \%$ to 97.6 and recommended fetal antigen testing as an alternative to urea breath test for screening of H.Pylori [29]. Calik Z, et al have reported $86.8 \%$ cases positive for $\mathrm{H}$. pylori infection. The reported sensitivity, specify, positive and negative predictive values were $92.45 \%, 81.25 \%, 97.02 \%$, and $61.90 \%$, respectively [15].

Falsafi $\mathrm{T}$, have reported a sensitivity and specificity of $94 \%, 86 \%$ and $96 \%, 98 \%$, respectively with two different stool antigen detection kits and emphasized the sustained reliability of different varieties of kits [16] Gramley WA, et al reported a sensitivity of $73 \%$ and specificity of $100 \%$ for stool antigen assay [17]. Guslandi $\mathrm{M}$ et al.[18] have reported sensitivity, specificity, and positive and negative likelihood ratios of HpSA to be $85 \%, 93 \%$, $89.7 \%$, and $90 \%$, respectively as compared to culture [13]. Segamwenge IL [30], in contrast to the other studies have reported a low overall sensitivity of $55.8 \%$, and specificity of $74.2 \%$.

Miftahussurur M,et al [10] in their review have emphasized that Stool antigen test (SAT) is one of the best methods to determine active H.Pylori infection. Even tough serology is more sensitive than stool antigen test, the major limitation is poor specificity and inability to distinguish active infection from previous infection. Shimoyama Tet al [31] in their review pointed out that, the performance of Stool antigen test is on par with serology, but cautioned that accuracy may be lower, if stool samples are unformed or watery.

Temperature and the interval between stool sample collection and measurement also reported to be affect the results of SATs. The choice of test kit depends on the sensitivity and specificity in each region and the circumstances of each patient. Queiroz DM, e reported a kappa coefficient of 0.90 (0.87 to 0.92$)$, similar to the current study and concluded stool monoclonal as a reliable alternative for other screening tests [32].

\section{Conclusions}

1. Faecal antigen test has shown good validity and reliability in diagnosis of H.pylori infection

2. Considering it's noninvasive nature and ease of conducting, this Faecal antigen test will be ideal choice in resource limited settings.

\section{Limitations}

1. Generalizability of the study findings to wider sections of the population is limited.

2 . The validity and reliability in different subsections based on key determining variables like age, gender and socio economic status etc. could not be evaluated, considering the smaller sample size.

\section{Recommendations}

1. Faecal antigen test shows good reliability and validity and can be considered as useful screening test in resource poor settings.

2. Further large scale studies in diverse population groups in India may throw light on performance of the test in these groups and enhance the generalizability

Conflict of interest: None declared. Funding: Nil, Permission from IRB: Yes

\section{References}

1. Ahmed N, Sechi LA. Helicobacter pylori and gastroduodenal pathology: new threats of the old friend. Annals of clinical microbiology and antimicrobials. 2005;4:1,doi.10.1186/1476-0711-4-1.

2. Ghoshal UC, Chaturvedi R, Correa P. The enigma of Helicobacter pylori infection and gastric cancer. Indian journal of gastroenterology : official journal of the Indian Society of Gastroenterology. 2010;29(3):95-100, doi.10. 1007 /s12664-010-0024-1.

3. Ghoshal UC, Chourasia D. Gastroesophageal Reflux Disease and Helicobacter pylori: What May $\mathrm{Be}$ the Relationship? J Neurogastroenterol Motil. 2010;16(3): 243-50, doi.10.5056/jnm.2010.16.3.243.

4. Katelaris PH, Tippett GH, Norbu P, Lowe DG, Brennan R, Farthing MJ. Dyspepsia, Helicobacter pylori, and peptic ulcer in a randomly selected population in India. Gut. 1992; 33(11):1462-6.

5. Romshoo GJ, Malik GM, Basu JA, Bhat MY, Khan AR. Prevalence of Helicobacter pylori Infection in Peptic Ulcer Patients of Highly Endemic Kashmir Valley. Diagnostic and therapeutic endoscopy. 1999; 6(1):31-6, doi.10.1155/dte.6.31.

6. Adlekha S, Chadha T, Krishnan P, Sumangala B. Prevalence of helicobacter pylori infection among patients undergoing upper gastrointestinal endoscopy in a medical college hospital in kerala, India. Annals of medical and health sciences research. 2013;3(4):559-63,doi.10.4103/ 2141-9248.122109. 


\section{Original Research Article}

7. Mujawar P, Nikumbh DB, Suryawanshi KH, Pagare PS, Surana A. Helicobacter pylori Associated Gastritis in Northern Maharashtra, India: A Histopathological Study of Gastric Mucosal Biopsies. Journal of clinical and diagnostic research : JCDR. 2015;9(6):Ec04-6, doi.10. $7860 /$ jcdr/2015/13306.6040.

8. Singh K, Ghoshal UC. Causal role of Helicobacter pylori infection in gastric cancer: an Asian enigma. World journal of gastroenterology. 2006;12(9):1346-51.

9. Thirumurthi S, Graham DY. Helicobacter pylori infection in India from a western perspective. The Indian journal of medical research. 2012;136(4):549-62.

10. Miftahussurur M, Yamaoka Y. Diagnostic Methods of Helicobacter pylori Infection for Epidemiological Studies: Critical Importance of Indirect Test Validation. BioMed research international. 2016;2016:4819423, doi.10.1155/ $2016 / 4819423$

11. Ricci C, Holton J, Vaira D. Diagnosis of Helicobacter pylori: invasive and non-invasive tests. Best practice \& research Clinical gastroenterology. 2007;21(2):299-313, doi.10.1016/j.bpg.2006.11.002.

12. Megraud F. Advantages and disadvantages of current diagnostic tests for the detection of Helicobacter pylori. Scandinavian journal of gastroenterology Supplement. $1996 ; 215: 57-62$

13. Iranikhah A, Ghadir MR, Sarkeshikian S, Saneian H, Heiari A, Mahvari M. Stool antigen tests for the detection of Helicobacter pylori in children. Iranian journal of pediatrics. 2013;23(2):138-42.

14. Makristathis A, Pasching E, Schutze K, Wimmer M, Rotter ML, Hirschl AM. Detection of Helicobacter pylori in stool specimens by PCR and antigen enzyme immunoassay. Journal of clinical microbiology. 1998; 36(9):2772-4

15. Calik Z, Karamese M, Acar O, Aksak Karamese S, Dicle Y, Albayrak F, et al. Investigation of Helicobacter pylori antigen in stool samples of patients with upper gastrointestinal complaints. Brazilian journal of microbiology : [publication of the Brazilian Society for Microbiology]. 2016;47(1):167-71, doi.10.1016/j. bjm. 2015.11.022.

16. Falsafi $\mathrm{T}$, Lavasani $\mathrm{P}$, Basardeh $\mathrm{I}$, Massarrat $\mathrm{S}$, Landarani Z. Evaluation of an Iranian Home-made Helicobacter pylori Stool Antigen ELISA Kit.
Jundishapur journal of microbiology. 2014;7(6):e10629, doi.10.5812/jjm.10629.

17. Gramley WA, Asghar A, Frierson HF, Jr., Powell SM. Detection of Helicobacter pylori DNA in fecal samples from infected individuals. Journal of clinical microbiology. 1999; 37(7):2236-40.

18. Guslandi M. Stool immunoassay for Helicobacter pylori is not specific enough. BMJ (Clinical research ed). $2000 ; 320(7248): 1541$.

19. Karadeniz RS, Ozdegirmenci O, Altay MM, Solaroglu A, Dilbaz S, Hizel N, et al. Helicobacter pylori seropositivity and stool antigen in patients with hyperemesis gravidarum. Infectious diseases in obstetrics and gynecology. 2006;2006:73073, doi.10.1155/ idog/ 2006/73073.

20. Kazemi S, Tavakkoli H, Habizadeh MR, Emami MH. Diagnostic values of Helicobacter pylori diagnostic tests: stool antigen test, urea breath test, rapid urease test, serology and histology. Journal of research in medical sciences : the official journal of Isfahan University of Medical Sciences. 2011;16(9):1097-104.

21. Khalifehgholi M, Shamsipour F, Ajhdarkosh $\mathrm{H}$, Ebrahimi Daryani N, Pourmand MR, Hosseini M, et al. Comparison of five diagnostic methods for Helicobacter pylori. Iranian journal of microbiology. 2013; 5(4):396401.

22. Kodama M, Murakami K, Okimoto T, Fukuda Y, Shimoyama T, Okuda M, et al. Influence of proton pump inhibitor treatment on Helicobacter pylori stool antigen test. World journal of gastroenterology. 2012;18(1):44-8, doi.10.3748/wjg.v18.i1.44.

23. Krausse R, Muller G, Doniec M. Evaluation of a rapid new stool antigen test for diagnosis of Helicobacter pylori infection in adult patients. Journal of clinical microbiology. 2008; 46 (6):2062-5, doi.10.1128/jcm. 02387-07.

24. Li YH, Guo H, Zhang PB, Zhao XY, Da SP. Clinical value of Helicobacter pylori stool antigen test, ImmunoCard STAT HpSA, for detecting $\mathrm{H}$ pylori infection. World journal of gastroenterology. 2004;10 (6):913-4.

25. MacKay WG, Williams CL, McMillan M, Ndip RN, Shepherd AJ, Weaver LT. Evaluation of protocol using gene capture and PCR for detection of Helicobacter pylori 
DNA in feces. Journal of clinical microbiology. 2003;41 (10):4589-93.

26. Malik GM, Kadla S, Mubarik M, Hussain T, Jeelani $\mathrm{G}$, Basu J, et al. Helicobacter pylori infection in endoscopic biopsy specimens of gastric cancer: a preliminary evaluation in a high risk population of kashmir valley. Diagnostic and therapeutic endoscopy. 1997; 4 (1):35-42, doi.10.1155/dte.4.35.

27. Ganguly M, Sarkar S, Ghosh P, Sarkar A, Alam J, Karmakar BC, et al. Helicobacter pylori plasticity region genes are associated with the gastroduodenal diseases manifestation in India. Gut pathogens. 2016; 8:10, doi.10.1186/s13099-016-0093-5.

28. Ghosh P, Sarkar A, Ganguly M, Raghwan, Alam J, De $\mathrm{R}$, et al. Helicobacter pylori strains harboring babA2 from Indian sub population are associated with increased virulence in ex vivo study. Gut pathogens. 2016;8:1, doi.10.1186/s13099-015-0083-z.

\section{Original Research Article}

29. Andrews J, Marsden B, Brown D, Wong VS, Wood E, Kelsey M. Comparison of three stool antigen tests for Helicobacter pylori detection. Journal of clinical pathology. 2003;56(10):769-71.

30. Segamwenge IL, Kagimu M, Ocama P, Opio K. The utility of the Helicobacter pylori stool antigen test in managing dyspepsia: an experience from a low resource setting. African health sciences. 2014;14(4):829-34, doi. 10. 4314/ahs.v14i4.9.

31. Shimoyama T. Stool antigen tests for the management of Helicobacter pylori infection. World journal of gastroenterology. 2013; 19(45): 8188-91, doi.10. 3748 /wjg.v19.i45.8188.

32. Queiroz DM, Saito M, Rocha GA, Rocha AM, Melo FF, Checkley W, et al. Helicobacter pylori infection in infants and toddlers in South America: concordance between [13C]urea breath test and monoclonal H. pylori stool antigen test. Journal of clinical microbiology. 2013;51(11):3735-40, doi.10.1128/jcm.01752-13.

\section{How to cite this article?}

Senthil Kumar K, Dinesh Kumar T, Balamuralee R, Anantharamakrishnan R. Validity and reliability of faecal antigen test in identifying h. Pylori infection in adults with dyspepsia. Int $J$ surg Orthopedics 2016;2(4):7984.doi:10.17511/ijoso.2016.i04.05. 